\title{
Economic forecast based on Markov chain
}

\author{
Jiya $\operatorname{Tian}^{1, \mathrm{a}}$, Yong Zhang ${ }^{1, \mathrm{~b}}$, Nan $\mathrm{Li}^{2, \mathrm{c}}$ \\ ${ }^{1}$ Electric Information College of Changchun Guanghua University, Changchun,130031,China \\ ${ }^{2}$ The Chinese people's Liberation Army Armored Force Technical University, Chuangchun, 130031, \\ China \\ aemail: 42683387@qq.com, bemail: 511304994@qq.com
}

Keywords: Markov chain; state transition probability; market share; expected profit

\begin{abstract}
Economic forecasting is very important for market forecast analysis and market management decision. The paper proposes the application of Markov chain in economic forecast. Firstly, give the Markov base theory. Secondly, discuss the process of economic forecast based on Markov chain. Finally, forecast the expected profit using real data. Experimental results show that Markov theory could be used in real economic environment. It has important guiding significance in marketing activities.
\end{abstract}

\section{Introduction}

In real economic life, a lot of uncertain things often occur because of the change of economic environment and business conditions. In order to study this situation, first of all we need to collect the information about the changes economic environment and so on. get the regular pattern of variation of economic environment. Suppose the regular pattern is correct in the coming period and will keep a long time. In order to easy express the theory, if the economic environment is different, it is called system in a different state.

In real economic environment, the system state has some relationship with its state in front of the time. The most basic relationship is the system state probability only has relationship with the system state probability in front of its time and has not relationship with other system state. This forecast problem is Markov forecast. Markov forecast is very coincide with the application in economic forecast.

\section{Markov chain}

The system state at time $t_{0}$ could decide the system states when $t>t_{0}$. Get the system state when $t>t_{0}$ need not the system state before $t_{0}$. The above phenomenon could be extend to random phenomenon. When a process has statistical law, we can introduce Markov character to analyze following the above principle. When the system status at $t_{0}$ is known, the system status at $t>t_{0}$ has no relationship with the system status before $t_{0}$. When we know the status now, its future is not dependent on the past.

Suppose the state space of stochastic process $\{X(t), t \in T\}$ is I. If the time $t$ of any $n$ value $t_{1}<t_{2}<\ldots<t_{n}, n \geq 3, t_{i} \in T$, when $X\left(t_{i}\right)=x_{i}, i \in I, \quad i=1,2, \cdots, n-1$, the conditional distribution function of $X\left(t_{n}\right)$ is the same with the Conditional distribution function of $X\left(t_{n}\right)$ when $X\left(t_{n-1}\right)=X_{n-1}$.

$$
\begin{gathered}
P\left\{X\left(t_{n}\right) \leq x_{n} \mid X\left(t_{1}\right)=x_{1}, X\left(t_{2}\right)=x_{2}, \cdots, X\left(t_{n-1}\right)<x_{n-1}\right\}= \\
P\left\{X\left(t_{n}\right) \leq x_{n} \mid X\left(t_{n-1}\right)=x_{n-1}\right\}_{\mathrm{x}_{\mathrm{n}}} \in \mathrm{R}
\end{gathered}
$$

or 


$$
\begin{gathered}
F_{t_{n}} \mid t_{1} \cdots t_{n}\left(x_{n}, t_{n} \mid x_{1}, x_{2}, \cdots, x_{n-1} ; t_{1}, t_{2}, \cdots, t_{n-1}\right)= \\
F_{t_{n}} \mid t_{n-1}\left(x_{n}, t_{n} \mid x_{n-1}, t_{n-1}\right)
\end{gathered}
$$

The process $\{X(t), t \in T\}$ is called Markov process.

When time and state are both discrete, the Markov process is called a Markov chain. The so-called Markov chain is a kind of random time series. Its future value only has relationship with its current value, and has no relationship with it past value.

\section{Economic forecast using Markov Chain}

Market demand status analysis. Status is the possible condition of the objective thing. Usually there are two ways to divide state. One is according to the objective things itself with the state boundaries to divide. Like the weather sunny, cloudy, rain and other state. The other is based on analysis of artificially divided. Such as market demand in accordance with the sales division is popular, slow-moving state. State division should pay attention to the analysis of the object of a comprehensive investigation understanding. Determine the market demand with the purpose of the analysis and decision makers need. According to the market demand state, market demand status generally includes selling, normal, slow-moving state, which is represented as $S_{i}(i=1,2, \cdots, N)$.

Calculate the initial state probability.The initial state probability is the probability of occurrence, which is approximately the frequency of state occurrence, which is expressed as $\mathrm{P}_{i}\left(\mathrm{P}_{\mathrm{i}}\right.$ $\left.\geqslant 0, \sum_{i=1}^{n} P_{i}=1\right)$. In probability theory, it has been proved that when the theory of state probability distribution is unknown, if the sample size is large enough, we can describe the theoretical distribution of the state with the same sample distribution. Thus, the state can be approximated by the state of the probability of occurrence of the estimated state. Suppose the analysis object has $\mathrm{n}$ states, which are expressed as $S_{i}(i=1,2, \cdots, N)$. In the known historical statistics, the number of state $S_{i}$ appears as $M_{i}$, then the frequency of $S_{i}$ is $F_{i}$.

$$
\begin{aligned}
& F_{i}=\frac{M_{i}}{N} \\
& N=\sum_{i=1}^{n} M_{i}
\end{aligned}
$$

Here $\mathrm{N}$ is the total number of states that appear in the known historical statistics .so the probability $P_{i}$ of status $S_{i}$ is as formula 5 and 6.

$$
\begin{aligned}
P_{i} \approx F_{i} & =\frac{M_{i}}{N}, i=1,2, \cdots, n \\
\sum_{\mathrm{i}=1}^{\mathrm{n}} \mathrm{P}_{\mathrm{i}} & =1
\end{aligned}
$$

One step transition probability of computing state.One step transition probability is expressed as 7.

$$
P_{i j}(i=1,2, \cdots, n ; j=1,2, \cdots, n)
$$

The state transition is the change of the objective things in one state to another. The state of an objective thing is not fixed. It is often change from one state to another state with the change of conditions. Such as a product in the market had been in the best state, but due to the change of new products or consumer spending habits may be converted into the unsalable goods.

Because the state transition is random, it is necessary to be described using probability. State transition probabilities are used to describe the probability of transition between different states. 
Objective things may be $S_{1}, S_{2}, \ldots S_{n}, \ldots, S_{i} \rightarrow S_{j}, \ldots, S_{i} \rightarrow S_{n}$. The most basic state transition probability is one step transition probability $P\left(S_{j} \mid S_{i}\right)$, which indicates the one step state probability from $S_{i}$ to $S_{j}$. It is denoted as $P_{i j}$.

$$
P_{i j}=P\left(S_{j} \mid S_{i}\right)=P\left(S_{i} \rightarrow S_{j}\right)
$$

If the thing has the $\mathrm{N}$ states, then starts from a certain state $S_{i}$, correspondingly has n one step states transition probability. The probability is respectively: $P_{i 1}, P_{i 2}, \cdots, P_{i j}, \cdots, P_{i n}$. When the theoretical distribution of the state transition probability is known, such as the sample size is large enough, the probability of the probability can be approximated by the frequency of each other. In the sample, the number of Si turning to $\mathrm{Sj}$ is Mij, the number of initial state in the sample is $\mathrm{Mi}$, then the number of Si is:

$$
\begin{aligned}
& P_{i j}=P\left(S_{j} \mid S_{i}\right) \approx F\left(S_{j} \mid S_{i}\right) \\
& =\frac{M_{i j}}{M_{i}}(i=1,2, \cdots n ; j=1,2, \cdots n)
\end{aligned}
$$

State transition probability matrix P.In order to get a n row n column, the probability of one step state transition probability of the thing is $n$.

$$
\begin{gathered}
S_{1} \\
P=S_{1} \\
S_{1} \\
S_{2} \\
\vdots \\
S_{j}
\end{gathered}\left[\begin{array}{cccccc}
P_{11} & P_{12} & \cdots & P_{1 j} & \cdots & P_{1 n} \\
P_{21} & P_{22} & \cdots & P_{2 j} & \cdots & P_{2 n} \\
\vdots & \vdots & \cdots & \vdots & \cdots & \vdots \\
S_{n} & P_{i 2} & \cdots & P_{i j} & \cdots & P_{i n} \\
\vdots & \vdots & \vdots & \vdots & \vdots & \vdots \\
P_{n 1} & P_{n 2} & \cdots & P_{n j} & \cdots & P_{n n}
\end{array}\right]
$$

$\mathrm{P}_{\mathrm{ij}} \geq 0, \sum_{\mathrm{j}=1}^{\mathrm{n}} \mathrm{P}_{\mathrm{ij}}=1, \quad \mathrm{I}=1,2, \cdots, \mathrm{n}$.

$\mathrm{P}$ is one step state transition probability matrix. If one step state transition probability matrix is $\mathrm{P}$, the k step state transition probability matrix is $P^{(k)}$, and the formula is

$$
P^{(k)}=P^{(k-1)} \bullet P=P \bullet P \cdots P
$$

The application of Markov prediction method. According to the state transition probability matrix, we can analyze and evaluate the demand of specific products in the market in the future.

\section{Experimental Results}

Market share forecast.Market share forecast is a very important part of economic forecast. The market share of the product and its changing trend directly affect the development of the enterprise.

Usually Markov method can be used to predict the short-term market conditions, can also be used to predict the stability under the condition of long-term market conditions. We analyze how to make use of the Markov forecast model to forecast the market share based on the PC sales cases.

Taking $\mathrm{X}$ enterprise as an example. A PC previous users have $72 \%$ still buy A, $12 \%$ transfer to buy B, $16 \%$ transfer purchase C. B PC previous users have $80 \%$ still buy B, $8 \%$ transfer to buy A, $12 \%$ transfer purchase C; C PC period of $85 \%$ of users still buy C, $10 \%$ transfer to buy A, $5 \%$ transferred to buy B.

The total market sales of PC are 800 , A is 250 , B is 250 and C is 300.

One step state transition probability matrix $\mathrm{P}$ is: 


$$
\mathrm{P}=\left[\begin{array}{lll}
0.72 & 0.12 & 0.16 \\
0.08 & 0.80 & 0.12 \\
0.10 & 0.05 & 0.85
\end{array}\right]
$$

The initial (previous) market share is $S(0)=[0.3125,0.3125,0.3750]$.

According to Markov predict model, $\mathrm{S}(1)=\mathrm{S}(0) \mathrm{P}=[0.288,0.306,0.406]$.

In conclusion, A, B, the PC market share has declined, and C PC market share has continued to climb. We can also get the future market share as follows:

Table 1 the market share change

\begin{tabular}{|l|l|l|l|}
\hline $\mathrm{K}$ (time) & $\mathrm{A}$ & $\mathrm{B}$ & $\mathrm{C}$ \\
\hline 0 & 0.313 & 0.313 & 0.375 \\
\hline 1 & 0.288 & 0.306 & 0.406 \\
\hline 2 & 0.272 & 0.300 & 0.428 \\
\hline 3 & 0.263 & 0.294 & 0.444 \\
\hline 4 & 0.257 & 0.289 & 0.454 \\
\hline$\ldots$ & & & \\
\hline $\mathrm{k}$ & 0.249 & 0.270 & 0.481 \\
\hline $\mathrm{K}+1$ & 0.249 & 0.270 & 0.481 \\
\hline
\end{tabular}

According to table 1, we can get the market share curve as figure 1.

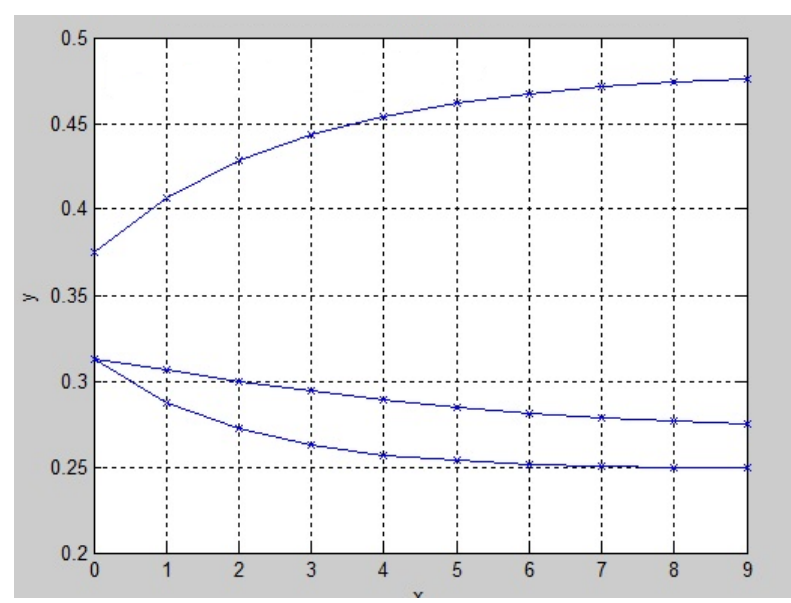

Fig 1 . The curve of market share

The first curve presents C PC, second curve presents B PC, and the third curve presents A PC. Figure 1 shows that as time goes on, the change is more slowly. At the end, the market share will be stable at one value.

Enterprise expected profit forecast. Suppose a company has a certain product, his annual sales divided into selling and slow-moving. When selling, the annual profit is 100 million yuan. When unsalable, the annual loss is 80 million yuan. Use one year as a period of time, if the manager does not take special measures, the state transition matrix is

$P=\left[\begin{array}{ll}0.7 & 0.3 \\ 0.4 & 0.6\end{array}\right]$,

If special measures are taken, the transfer matrix of the state is

$Q=\left[\begin{array}{ll}0.8 & 0.2 \\ 0.6 & 0.4\end{array}\right]$

But it required to pay the cost of 20 million yuan per year.

Assume that a year for sales, in the following cases, in order to obtain the maximum profit, the company adopt various strategies:

\section{Operating only 2 years and take no measure every year}

Because it is a regular business for 2 years, it can be used as the sum of the average profit of 
each period as the decision-making goal. Get the sum by backward induction. Represents the received average profit of selling and unsalable using $r_{1}, r_{2}$ respectively. Represents the total profit from first to the $m$ stage of selling and unsalable using $r_{1}(m), r_{2}(m)$ respectively.

Because the manager does not take special measures, the state transition matrix is

$P=\left[\begin{array}{ll}0.7 & 0.3 \\ 0.4 & 0.6\end{array}\right]$

$r_{i}=r_{i 1} P_{i 1}+r_{i 2} P_{i 2} i=1,2$

$r_{1}(m)=r_{1}+P_{11} r_{1}(m+1)+P_{12} r_{2}(m+1)$

$r_{2}(m)=r_{2}+P_{21} r_{1}(m+1)+P_{22} r_{2}(m+1)$

Then $r_{2}^{(1)}=r_{21}^{(1)} P_{21}^{(1)}+r_{22}^{(1)} P_{22}^{(1)}=100 \times 0.4-80 \times 0.6=-8$

$R_{0}^{(1)}=\left[\begin{array}{c}46 \\ -8\end{array}\right]$

$R^{(1)}(3)=0$

$R^{(1)}(2)=\left[\begin{array}{c}46 \\ -8\end{array}\right]+\left[\begin{array}{ll}0.7 & 0.3 \\ 0.4 & 0.6\end{array}\right]\left[\begin{array}{l}0 \\ 0\end{array}\right]=\left[\begin{array}{c}46 \\ -8\end{array}\right] R^{(1)}(1)=\left[\begin{array}{c}46 \\ -8\end{array}\right]+\left[\begin{array}{ll}0.7 & 0.3 \\ 0.4 & 0.6\end{array}\right]\left[\begin{array}{c}46 \\ -8\end{array}\right]=\left[\begin{array}{c}75.8 \\ 5.6\end{array}\right]$

Using this method company can get an average profit of 5.6 million yuan.

Operating only 2 years and take measure every year

If special measures are taken, the transfer matrix of the state is

$Q=\left[\begin{array}{ll}0.8 & 0.2 \\ 0.6 & 0.4\end{array}\right]$

$r_{1}^{(2)}=r_{11}^{(2)} P_{11}^{(2)}+r_{12}^{(2)} P_{12}^{(2)}=80 \times 0.8-100 \times 0.2=44$

$r_{21}^{(2)}=r_{21}^{(2)} P_{21}^{(2)}+r_{22}^{(2)} P_{22}^{(2)}=80 \times 0.6-100 \times 0.4=8$

$R_{0}^{(2)}=\left[\begin{array}{c}44 \\ 8\end{array}\right] R^{(1)}(3)=0$

$R^{(2)}(2)=\left[\begin{array}{c}44 \\ 8\end{array}\right]+\left[\begin{array}{ll}0.8 & 0.2 \\ 0.6 & 0.4\end{array}\right]\left[\begin{array}{l}0 \\ 0\end{array}\right]=\left[\begin{array}{c}44 \\ 8\end{array}\right]$

$R^{(2)}(1)=\left[\begin{array}{c}44 \\ 8\end{array}\right]+\left[\begin{array}{cc}0.8 & 0.2 \\ 0.6 & 0.4\end{array}\right]\left[\begin{array}{c}44 \\ 8\end{array}\right]=\left[\begin{array}{c}44 \\ 8\end{array}\right]+\left[\begin{array}{c}36.8 \\ 29.6\end{array}\right]=\left[\begin{array}{c}80.8 \\ 37.6\end{array}\right]$

Using this method company can get an average profit of 37.6 million yuan.

\section{Long term business and take no measure every year}

Represents the received average profit of selling and unsalable using $r_{1}, r_{2}$ respectively.

Represents the $n$ stage probability of selling and unsalable using $\pi_{1}(n), \pi_{2}(n)$ respectively.

$$
\begin{gathered}
E=\lim _{n \rightarrow \infty} \frac{1}{n} \sum_{n=1}^{n}\left[r_{1} \pi_{1}(i-1)+r_{2} \pi_{2}(i-1)\right] \\
=\lim _{n \rightarrow \infty}\left[r_{1} \pi_{1}(n-1)+r_{2} \pi_{2}(n-1)\right]=r_{1} \pi_{1}+r_{1} \pi_{2} \\
\left\{\begin{array}{c}
0.7 \pi_{1}+0.4 \pi_{2}=\pi_{1} \\
\pi_{1}+\pi_{2}=1
\end{array}\right.
\end{gathered}
$$


$100 \times \frac{4}{7}-80 \times \frac{3}{7}=22.86$

Using this method company can get an average profit of 22.86 million yuan.

\section{Long term business and take measure every year}

$\left\{\begin{array}{c}0.8 \pi_{1}+0.6 \pi_{2}=\pi_{1} \\ \pi_{1}+\pi_{2}=1\end{array}\right.$

$\pi_{1}=\frac{3}{4}, \pi_{2}=\frac{1}{4}$

$80 \times \frac{3}{4}-100 \times \frac{1}{4}=35$

Using this method company can get an average profit of 35 million yuan.

Statistic the average profit in table 2 . The money unit is million yuan.

Table 2 the result of every mode

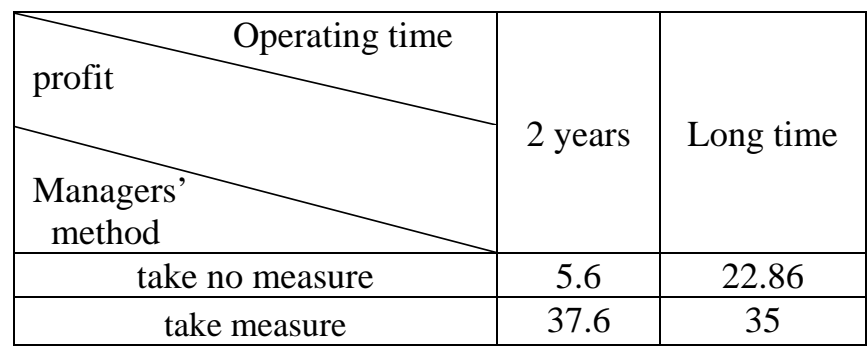

Compare the profits of the above strategy, the optimal strategy for each year to take special strategies.

\section{Summary}

Facing the unpredictable market take flexible strategy in enterprise management is very important of. Through the example analysis, enterprise in certain circumstances whether to take special measures, the benefits to the enterprise will have a huge impact. It requires enterprise management and improves management level and grasp the flexible business strategy and establish the correct business philosophy only in this way can we in a rapidly changing business in an invincible position. Markov chain is a method to study the trend of random events. Due to the needs of the corporate market by the combined effects of a variety of factors and is random, generally meet no aftereffect requirements and Markov method in product market analysis has wide applicability. Large number of analysis of real examples proves that it is reliable by Markov forecast. This method is not only applicable in the market management. As long as the condition meets Markov dynamic system it can use Markov chain to analyze.

\section{Acknowledgement}

I would like to express my gratitude to all those who have helped me during the working of this paper. I gratefully acknowledge the finding of this study by the Department of Education of Jilin Province project.

\section{References}

[1] BAO F X, CHEN H L. Economics Forecast and Decision Method[M].Jinan University Press.2006.6

[2] LI C M,LIU SH CH, SHEN L SH.Economic forecast in 100 cases[M].Liaoning People's Publishing House.1986. 
[3] HOU H X, LU Y L, CHEN ZH.Calculation of the model of B2-NiAlInverse defect Based on Markov chain[J].Rare Metal Materials and Engineering. 2013,42(7):1433-1437.

[4] Biswas B,R Ram.Military expenditures and economic growth in less developed countries: An augmented model and further evidence[J]. Economic Development and CulturalChange, 1986,34:361-372.

[5] Deger,S.,Smith,R.P.Military expenditures and growth in less developed countries[J].Journalof Conflict Resolution,1983,27(2):335-353.

[6] Rasler,K.,Thompson , W.R..Defense burdens, capital formation , and economicgrowth[J]. Journal of Conflict Resolution,1998,32(1):61- 86.

[7] Pelagatti, M.M. Duration dependent markov-switching vectorautoregression: properties, bayesian inference, software and application[Z] . Working Paper, 2005.

[8] WANG Y D. Effect of population aging on economic forecast[J].Jinan Journal(Philosophy and Social Sciences),2015,(11):47-53. 